\title{
PUPILLOMETRY AND ANALGESIA NOCICEPTION INDEX (ANI) UTILITY DURING EPIDURAL AND GENERAL ANAESTHESIA.
}

Lucena Delgado J., Abad Gurumeta A., Huercio Martínez I., López Quesada T. *, Brogly N., Gilsanz Rodríguez F. H.U. La Paz, Dept of Anaesthesiology \& Intensive Care, Madrid, Spain, ${ }^{2}$

* H.U. La Paz, Dept of Surgery, Madrid, Spain

BACKGROUND: Optimizing an adequate level of analgesia at the right time is a challenge for the anaesthesiologist and an indicator of good quality care. New monitors have been proposed based on the sympathetic (pupillometry) and parasympathetic (Analgesia Nociceptive Index $\mathrm{ANI}^{\circledR}$ ) nociceptive response.

\section{CASE REPORT}

Female, 36 years old, ASA I. Previous history of right femoral nerve lesion after a previous surgical intervention of a retroperitoneal femorocutaneal nerve schwannoma and scheduled for nerve surgical reconstruction.

General anaesthesia combined with epidural technique at L4L5 level (initial bolus of $10 \mathrm{ml}$ L-Bupivacaine $0.5 \%$ was administered, and a 0,25\% I-bupivacaine infusion was maintained at a $10 \mathrm{ml} / \mathrm{h}$ rate). TIVA-TCl of propofol and remifentanil (Ce $2.5 \mathrm{mcg} / \mathrm{ml}$ and $2 \mathrm{ng} / \mathrm{ml}$ respectively) plus rocuronium boluses were administered according to a neuromuscular monitor (Veryark TOF $^{\circledR}$ ).

Algiscan ${ }^{\circledR}$ pupillometer (pupil diameter variation with induced or surgical stimulus) and $\mathrm{ANI}^{\circledR}$ monitoring (heart rate variability) to assess analgesia levels were used.

Both systems showed good levels of analgesia at baseline and during surgery (RDP pupilometry: null during first incision; PPI in axillary electrodes: $5-7$ with $17-54 \%$ variability); ANI (80-96), making it possible to reduce remifentanil from 2.5 to $1.5 \mathrm{ng} / \mathrm{ml}$ Ce. BIS (Bispectral Index) values didn't exceed 60, and the patient remained hemodynamically stable. The epidural infusion was maintained at a rate of $7 \mathrm{ml} / \mathrm{h}$ for four days after surgery without any needs of extra opioids (EVA score: 0 ).

\section{DISCUSSION}

$\Longrightarrow$ Pupillometry and ANI allowed to anticipate and determine an adequate analgesia during surgery, thus allowing to use lower doses of remifentanil.

$\Longrightarrow$ It could also help to assess a satisfactory epidural technique under general anaesthesia.

$\Rightarrow$ Remifentanil doses were better adjusted following the variations of ANI monitor (1).

$\Longrightarrow$ Other studies showed that pupillometry might reduce pain and analgesic consumption in the postoperative period (2).

\section{Learning points:}

ANI and pupillometry RDP could be useful to test the efficacy of epidural blocks during general anaesthesia. Pupillometry PPI and tetanus could predict response to noxious stimuli. ANI could monitor level of nociceptive response continuously. 